Case Report

\title{
Multicentric Castleman's Disease, Associated with Idiopathic Thrombocytopenic Purpura
}

\author{
Ruchi Sood, ${ }^{1}$ Harris C. Taylor, ${ }^{1,2}$ and Hamed Daw ${ }^{3}$ \\ ${ }^{1}$ Fairview Hospital, Cleveland Clinic Health System, Cleveland, OH 44111, USA \\ ${ }^{2}$ Case Western University School of Medicine, Cleveland, OH 44111, USA \\ ${ }^{3}$ Hematology-Oncology, Fairview Hospital, Cleveland Clinic Health System, Cleveland, OH 44111, USA \\ Correspondence should be addressed to Ruchi Sood; drruchisood@yahoo.com
}

Received 25 April 2013; Accepted 27 May 2013

Academic Editors: E. Bissé, R. Herrmann, M.-C. Kyrtsonis, and A. Ohsaka

Copyright (C) 2013 Ruchi Sood et al. This is an open access article distributed under the Creative Commons Attribution License, which permits unrestricted use, distribution, and reproduction in any medium, provided the original work is properly cited.

\begin{abstract}
The most common cause of a neck mass in young adults is hyperplastic lymphadenopathy consequent to infection and inflammation. Castleman's disease (CD), an unusual benign lymphoproliferative disorder, infrequently causes neck masses. It occurs in unicentric (UCD) and multicentric (MCD) forms and is associated with human immunodeficiency virus (HIV), human herpes virus 8 (HHV-8), and Kaposi's sarcoma. We present the third known association between MCD and previous immune thrombocytopenia in the absence of HIV and HHV-8 infection and review its association with other autoimmune disorders and attendant implications for pathogenesis. Finally, we summarize the current approach to therapy.
\end{abstract}

\section{Case Presentation}

A 27-year-old female with a history of asthma, presented with diffuse ecchymoses and nosebleeds in 2006 . Her platelet count was as low as $3 \times 10^{9} / \mathrm{L}$ having decreased from $112 \times$ $10^{9} / \mathrm{L}$ in 2005 . Her white cell count was $7.5 \times 10^{9} / \mathrm{L}$ and hemoglobin was $15.2 \mathrm{~g} / \mathrm{dL}$. HIV testing was negative, and no new medications had been started. Because of the severe isolated decline in platelet count, her thrombocytopenia was thought to be immune thrombocytopenia. She was begun on intravenous steroids and immunoglobulins. All signs of bleeding resolved but the platelet count started to drop while she was on the prednisone taper. She eventually required splenectomy after which her platelets increased to $461 \times 10^{9} / \mathrm{L}$. Her histological findings were compatible with immune thrombocytopenia. On follow-up visit 5 months later, she presented with significant episodes of dental bleeding and bruising and her platelet count had decreased to as low as $2 \times$ $10^{9} / \mathrm{L}$. She was started on rituximab only chemotherapy after which she remained in complete remission.

In March 2012, she presented with a three-month history of a growing, right lower neck mass. She denied any history of bleeding, fever, chills, night sweats, or weight loss. Examination revealed an afebrile female with hard, fixed, painless, right cervical lymphadenopathy measuring $4 \times 2 \mathrm{~cm}$. There were no other palpable lymph nodes. WBC was $11.23 \times$ $10^{9} / \mathrm{L}$ (34\% segmented neutrophils, $49 \%$ lymphocytes, $5 \%$ reactive lymphocytes, $7 \%$ monocytes, $5 \%$ eosinophils, and $0 \%$ basophils), Hgb $12.7 \mathrm{~g} / \mathrm{dL}$, and platelets $415 \times 10^{9} / \mathrm{L}$. Her comprehensive metabolic panel, serum protein electrophoresis, and lactate dehydrogenase were unremarkable. Pathology of the excised node revealed marked angiofollicular hyperplasia consistent with the hyaline vascular variant of $\mathrm{CD}$ (Figure 1). Contrast enhanced CT scan of the chest and abdomen showed bilateral axillary adenopathy of approximately $3 \mathrm{~cm}$ and mild bilateral superficial inguinal adenopathy. PET scan showed intense activity at the base of the tongue, consistent with lingual adenopathy, causing significant mass effect on the oropharyngeal airway. SUV max was 8.2 (Figure 2). There were numerous enlarged bilateral jugular, axillary, subcarinal, hilar, and inguinal lymph nodes. The right pelvic wall and parts of the stomach, large and small intestine also demonstrated mild to moderate fluorodeoxyglucose (FDG) uptake consistent with MCD (Figure 3). HIV antibodies and Western 


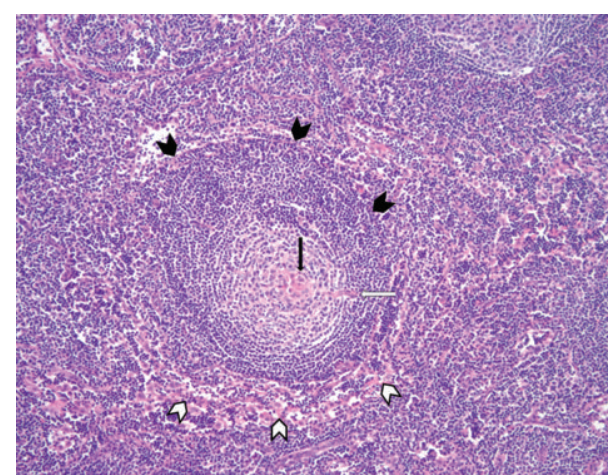

FIGURE 1: Marked angiofollicular hyperplasia representing hyaline vascular variant. Concentric "onion skin pattern" of peripheral lymphocytes (black arrow heads) surrounding a pale centered follicle (thin black arrow). Vascular proliferation (white arrow heads) is seen with capillaries demonstrating thickened walls and prominent endothelial cells. Penetrating hyalinized small vessel gives follicle a lollipop-like appearance (thin white arrow).

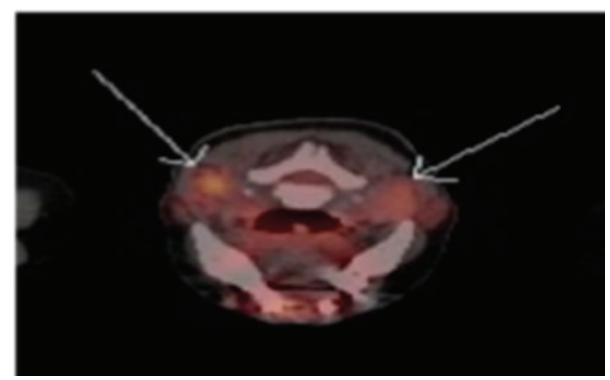

FIGURE 2: Before treatment: PET scan at the base of tongue, showing lingual adenopathy (White arrows).

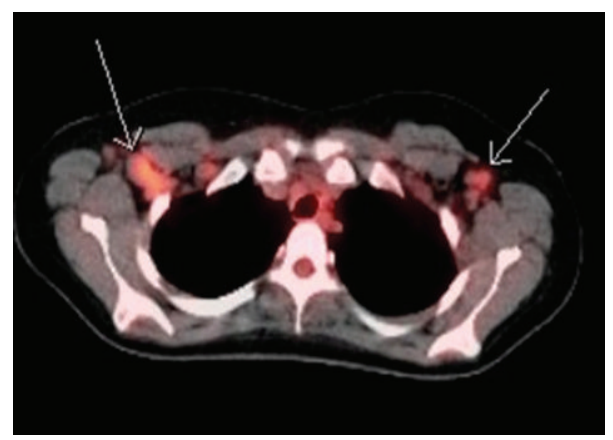

FIGURE 3: Before treatment: whole body scan with cut through the level of the lungs, showing axillary lympadenopathy (White arrows).

Blot were negative as was $\mathrm{HHV}-8$ testing by immunohistochemistry and PCR. Serum IgG was $1065 \mathrm{mg} / \mathrm{dL}$, IgA $366 \mathrm{mg} / \mathrm{dL}$, and IgM $122 \mathrm{mg} / \mathrm{dL}$.

She was started on rituximab chemotherapy $\left(375 \mathrm{mg} / \mathrm{m}^{2}\right)$ intravenously once weekly for 4 doses. Repeat PET scan done three months later showed decreased uptake at the base of tongue with an SUV max of 6.1 (Figure 4). Likewise, significant decrease in uptake of FDG was seen in the bilateral

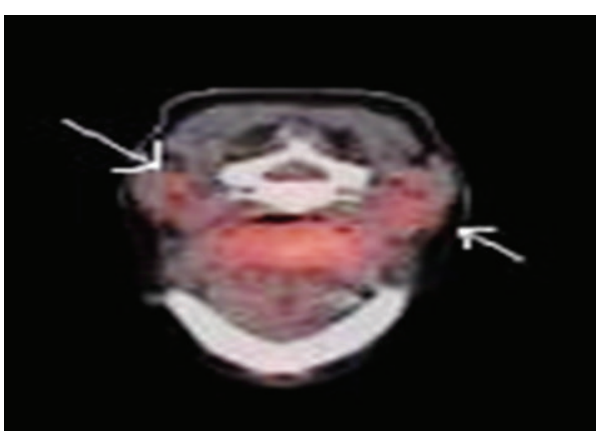

FIgURE 4: After treatment: PET scan at the base of tongue, showing resolution of previous noted lingual adenopathy (White arrows).

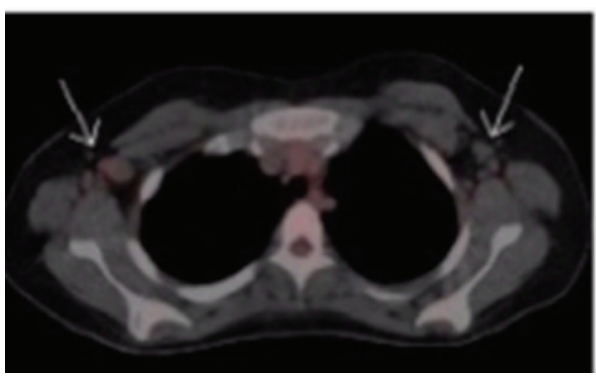

FIGURE 5: After treatment: whole body scan with cut through the level of the lungs, showing resolution of previously noted axiallary lymphadenopathy (White arrows).

jugular, axillary, subcarinal, and hilar nodes as well as the right pelvic wall, small and large bowel (Figure 5).

Her last followup was seven months later, and she was found to be asymptomatic.

\section{Discussion}

CD is also known as angiofollicular lymph node hyperplasia, giant lymph node hyperplasia, angiomatous lymphoid hamartoma, lymph node hamartoma, and benign giant lymphoma. The first case report of MCD was published in 1954 [1]. Two years later, Castleman described 13 patients with unicentric hyaline vascular CD of the chest [2]. Since it is a rare disease, there is no reliable information on its incidence [3]. It typically presents as a mediastinal mass and primarily involves the lymphatic tissue [4]. Extralymphatic sites of involvement include the lungs, larynx, parotid glands, pancreas, meninges, and muscles [5].

There are two major histopathogenetic types, hyaline vascular (HV) and the plasma cell (PC) variant. An intermediate form has also been described [6]. The HV type, which represents $90 \%$ of the cases, is characterized by follicular abnormalities and abundant interfollicular vascularization. The PC variant is characterized by hyperplastic germinal centers with plasma cell infiltration in the intervening areas.

The HV is considered to be an early form of the disease, whereas the PC variant is considered to be a mature form of the disease and is believed to be related to a stronger immunological response [7]. 
UCD, the less aggressive form of the disorder, presents as a solitary lesion. It is usually seen in young and middle aged patients without any sex predilection. The HV type is unicentric in $90 \%$ of the cases [8]. In contrast, MCD presents as generalized lymphadenopathy and is frequently associated with hepatosplenomegaly and constitutional symptoms. Anemia, hypoalbuminemia, and hypergammaglobulinemia are also common [9]. It is strongly associated with immunosuppression as in HIV and HHV-8 infection [10]. MCD ordinarily occurs in the fourth or fifth decades but may occur at younger ages in people who are HIV positive [11]. The PC variant is the predominant pathologic pattern in this type.

The etiology of $\mathrm{CD}$ remains unknown although both immunodeficiency and autoimmunity have been proposed. Chronic inflammation resulting from exposure to an unknown antigen has been supported by the presence of excessive serum levels of interleukin -6 (IL-6), a cytokine with pleiotropic effects on the immune system and hematopoiesis. Some believe it may play a central role in the pathophysiology of CD [12-14]. The association of $\mathrm{CD}$ with autoimmune disorders including myasthenia gravis [15], Evans' syndrome [16], vitiligo [17], coeliac disease [18], Graves' disease [19], and ulcerative colitis [20] suggests a possible autoimmune pathology. Of considerable interest, there are two previous reports of the association between $\mathrm{CD}$ and immune thrombocytopenia [21, 22]. However, it is not clear if autoimmunity is the underlying cause or result of CD [23]. Since our patient had a previous underlying autoimmune disorder in the form of immune thrombocytopenia, it appears as if an autoimmune response may be the cause in our patient. However, the possibility that this represents a chance association should be acknowledged.

The mainstay of treatment for UCD is complete surgical resection. Rarely, local recurrence has been reported [24]. In the case of partially resected lesions, the outcome is favorable, since patients may remain asymptomatic for years. Radiotherapy is the best option when surgical resection is not possible [25]. For MCD, complete surgical debulking is rarely possible. There is no definitive treatment as no randomized controlled trials have been performed due to its rarity. The available literature on MCD therapy consists mainly of single case reports and case series. Rituximab, a monoclonal antiCD 20 antibody, has significant activity against both HIV positive and negative MCD, even when used as salvage therapy. It was first introduced for the treatment of HIV positive patients with MCD after chemotherapy-induced remission [26].

Most MCD cases treated to date with rituximab have been HIV and HHV-8 positive patients. To our knowledge, approximately seven HIV negative patients with MCD have been treated with rituximab [26-33]. Rituximab was chosen in our patient as the first-line treatment since she also had a history of immune thrombocytopenia.

\section{Conclusion}

MCD is usually seen in the fourth and fifth decades of life. It is uncommon to encounter in a 27-year-old female in the absence of HIV or HHV-8 infection. Although infrequent, it is well known that hematological abnormalities, including anemia, leukopenia, or thrombocytopenia, can be encountered during the clinical course of CD [34-36]. However, the presence of $\mathrm{CD}$ during the clinical course of immune thrombocytopenia has been rarely described [21,22].

\section{Conflict of Interests}

The authors declare that they have no conflict of interests.

\section{Authors' Contribution}

All authors meet criteria for authorship, had access to the data, and participated in writing the paper. In addition, Dr. Hamed Daw was involved in major decision making during treatment of the patient. Dr. Ruchi Sood is a major contributor in analyzing the data and reviewing the literature. Dr. Harris Taylor is a major contributor in critically revising the paper for important intellectual content.

\section{Disclosure}

The case report is original and has not been previously published nor is it under consideration elsewhere. No permission to reproduce the pathology slide is required, as it does not disclose the patient's identity.

\section{References}

[1] B. Castleman and V. W. Towne, "Case records of the Massachusetts General Hospital: case no. 40231," The New England Journal of Medicine, vol. 250, pp. 1001-1005, 1954.

[2] B. Castleman, L. Iverson, and V. P. Menendez, "Localized mediastinal lymph node hyperplasia resembling thymoma," Cancer, vol. 9, pp. 822-830, 1956.

[3] B. Roca, "Castleman's disease: a review," AIDS Reviews, vol. 11, no. 1, pp. 3-7, 2009.

[4] I. S. Izuchukwu, K. Tourbaf, and M. C. Mahoney, "An unusual presentation of Castleman's disease: a case report," BMC Infectious Diseases, vol. 3, article 20, 2003.

[5] D. Bonekamp, K. M. Horton, R. H. Hruban, and E. K. Fishman, "Castleman disease: the great mimic," Radiographics, vol. 31, no. 6, pp. 1793-1807, 2011.

[6] D. D. Weisenburger, B. N. Nathwani, C. D. Winberg, and H. Rappaport, "Multicentric angiofollicular lymph node hyperplasia: a clinicopathologic study of 16 cases," Human Pathology, vol. 16, no. 2, pp. 162-172, 1985.

[7] B. Castleman, L. Iverson, and V. P. Menendez, "Localized mediastinal lymph node hyperplasia resembling thymoma," Cancer, vol. 9, no. 4, pp. 822-830, 1956.

[8] H. L. Tey and M. B. Y. Tang, "A case of paraneoplastic pemphigus associated with Castleman's disease presenting as erosive lichen planus," Clinical and Experimental Dermatology, vol. 34, no. 8, pp. e754-e756, 2009.

[9] A. Guihot, L. J. Couderc, F. Agbalika et al., "Pulmonary manifestations of multicentric Castleman's disease in HIV infection: a clinical, biological and radiological study," European Respiratory Journal, vol. 26, no. 1, pp. 118-125, 2005. 
[10] D. A. Lowenthal, D. A. Filippa, M. E. Richardson, M. Bertoni, and D. J. Straus, "Generalized lymphadenopathy with morphologic features of Castleman's disease in an HIV-positive man," Cancer, vol. 60, no. 10, pp. 2454-2458, 1987.

[11] A. Waterston and M. Bower, "Fifty years of multicentric Castleman's disease," Acta Oncologica, vol. 43, no. 8, pp. 698-704, 2004.

[12] G. Frizzera, "Castleman's disease and related disorders," Seminars in Diagnostic Pathology, vol. 5, no. 4, pp. 346-364, 1988.

[13] K. D. Markou, J. K. Goudakos, G. Psillas et al., "Castleman's disease of the neck: report of a case and review of the literature," B-ENT, vol. 5, no. 3, pp. 189-193, 2009.

[14] J. T. Beck, S. M. Hsu, J. Wijdenes et al., "Brief report: alleviation of systemic manifestations of Castleman's disease by monoclonal anti-interleukin-6 antibody," New England Journal of Medicine, vol. 330, no. 9, pp. 602-605, 1994.

[15] S. K. Lee, D. H. Kim, and B. S. Son, "Castleman's disease with myasthenia gravis," The Korean Journal of Thoracic and Cardiovascular Surgery, vol. 45, no. 3, pp. 199-201, 2012.

[16] A. Muela Molinero, B. Ballesteros del Rio, V. Sandoval Guerra, and J. Llor Baños, "Evans syndrome as presentation of multicenter Castleman disease," Revista Clinica Espanola, vol. 203, no. 12, pp. 616-617, 2003.

[17] J. H. Marsh, D. S. Colbourn, V. Donovan, and H. Staszewski, "Systemic Castleman's disease in association with Evan's syndrome and vitiligo," Medical and Pediatric Oncology, vol. 18, no. 2, pp. 169-172, 1990.

[18] M. H. Thoufeeq and M. J. Perry, "Castleman's disease in a patient with celiac disease," Indian Journal of Gastroenterology, vol. 26, no. 4 , article 187, 2007.

[19] M. Loy, E. Perra, P. Siotto et al., "Gray-scale and color Doppler sonographic findings in a case of mesenteric Castleman's disease incidentally detected in a patient with Graves' disease," Journal of Clinical Ultrasound, vol. 33, no. 7, pp. 356-359, 2005.

[20] D. Browne, E. N. Barton, K. O. Barrow, N. P. Williams, and B. Hanchard, "Multicentric angiofollicular lymph node hyperplasia in ulcerative colitis: a case report," West Indian Medical Journal, vol. 45, no. 1, pp. 34-36, 1996.

[21] K. Higashi, Y. Matsuki, T. Hidaka, S. Aida, K. Suzuki, and H. Nakamura, "Primary Sjogren's syndrome associated with hyaline-vascular type of Castleman's disease and autoimmune idiopathic thrombocytopenia," Scandinavian Journal of Rheumatology, vol. 26, no. 6, pp. 482-484, 1997.

[22] K. Ibrahim, I. Maghfoor, A. Elghazaly, N. Bakshi, S. Y. Mohamed, and M. Aljurfa, "Successful treatment of steroidrefractory autoimmune thrombocytopenia associated with Castleman disease with anti-CD-20 antibody (rituximab)," Hematology/Oncology and Stem Cell Therapy, vol. 4, no. 2, pp. 100-102, 2011.

[23] G. de Marchi, S. de Vita, M. Fabris, C. A. Scott, and G. Ferraccioli, "Systemic connective tissue disease complicated by Castleman's disease: report of a case and review of the literature," Haematologica, vol. 89, no. 4, article ECR03, 2004.

[24] N. Talat, A. P. Belgaumkar, and K. M. Schulte, "Surgery in castlemans disease: a systematic review of 404 published cases," Annals of Surgery, vol. 255, no. 4, pp. 677-684, 2012.

[25] M. Grandadam, N. Dupin, V. Calvez et al., "Exacerbations of clinical symptoms in human immunodeficiency virus type 1-infected patients with multicentric Castleman's disease are associated with a high increase in Kaposi's sarcoma herpesvirus DNA load in peripheral blood mononuclear cells," Journal of Infectious Diseases, vol. 175, no. 5, pp. 1198-2001, 1997.
[26] M. Corbellino, G. Bestetti, C. Scalamogna et al., "Long-term remission of Kaposi sarcoma-associated herpesvirus-related multicentric Castleman disease with anti-CD20 monoclonal antibody therapy," Blood, vol. 98, no. 12, pp. 3473-3475, 2001.

[27] D. Gholam, J. M. Vantelon, A. Al-Jijakli, and J. H. Bourhis, "A case of multicentric Castleman's disease associated with advanced systemic amyloidosis treated with chemotherapy and anti-CD20 monoclonal antibody," Annals of Hematology, vol. 82, no. 12, pp. 766-768, 2003.

[28] M. Ide, E. Ogawa, K. Kasagi, Y. Kawachi, and T. Ogino, "Successful treatment of multicentric Castleman's disease with bilateral orbital tumour using rituximab," British Journal of Haematology, vol. 121, no. 5, pp. 818-819, 2003.

[29] P. Nicoli, U. Familiari, M. Bosa et al., "HHV8-positive, HIVnegative multicentric Castleman's disease: early and sustained complete remission with rituximab therapy without reactivation of Kaposi sarcoma," International Journal of Hematology, vol. 90, no. 3, pp. 392-396, 2009.

[30] J. M. Cervera Grau, G. G. Esquerdo, C. L. Ferrándiz, H. B. Garcia, M. D. Castellano, and P. F. Moreno, "Complete remission in a pancytopenic HIV negative, HHV-8 positive patient with multicentric Castleman's disease induced with antiCD20," Clinical and Translational Oncology, vol. 8, no. 7, pp. 540-541, 2006.

[31] M. Ide, Y. Kawachi, Y. Izumi, K. Kasagi, and T. Ogino, "Longterm remission in HIV-negative patients with multicentric Castleman's disease using rituximab," European Journal of Haematology, vol. 76, no. 2, pp. 119-123, 2006.

[32] E. M. Ocio, F. M. Sanchez-Guijo, M. Diez-Campelo et al., "Efficacy of rituximab in an aggressive form of multicentric Castleman disease associated with immune phenomena," American Journal of Hematology, vol. 78, no. 4, pp. 302-305, 2005.

[33] M. Marietta, S. Pozzi, M. Luppi et al., "Acquired haemophilia in HIV negative, HHV-8 positive multicentric Castleman's disease: a case report," European Journal of Haematology, vol. 70, no. 3, pp. 181-182, 2003.

[34] H. Anderson, M. Harris, S. E. Walsh, J. B. Houghton, and G. R. Morgenstern, "Autoimmune cytopenias in Castleman's disease," The American Journal of Clinical Pathology, vol. 94, no. 1, pp. 101-104, 1990.

[35] S. Suwannaroj, S. L. Elkins, and R. W. McMurray, "Systemic lupus erythematosus and Castleman's disease," Journal of Rheumatology, vol. 26, no. 6, pp. 1400-1403, 1999.

[36] J. P. Quinn, O. M. Gilligan, and M. Horgan, “Evan's syndrome complicating multicentric Castleman's disease-dramatic response to rituximab," European Journal of Haematology, vol. 73, no. 5, pp. 384-385, 2004. 


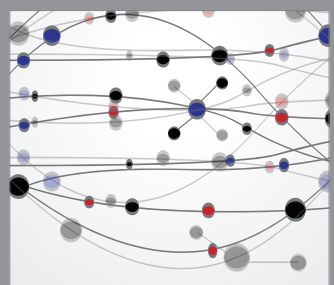

The Scientific World Journal
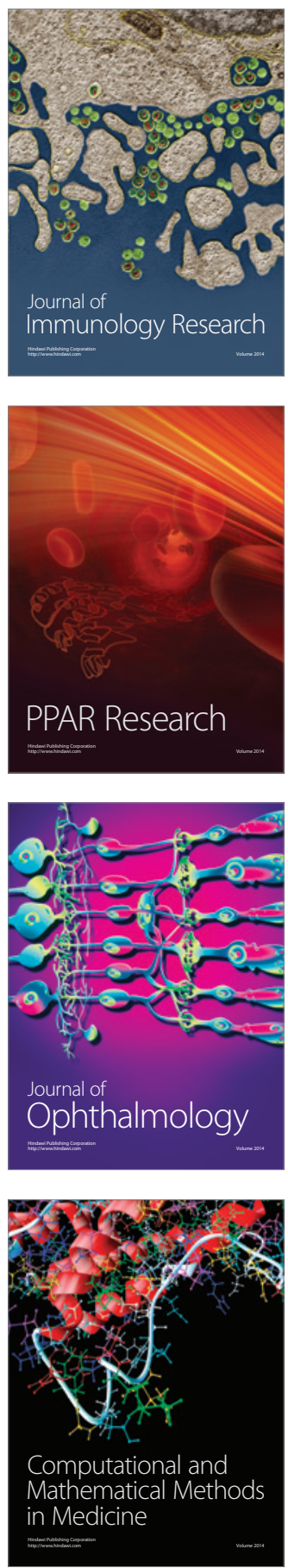

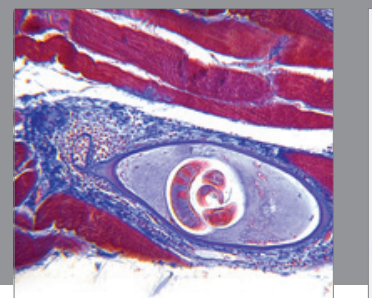

Gastroenterology

Research and Practice
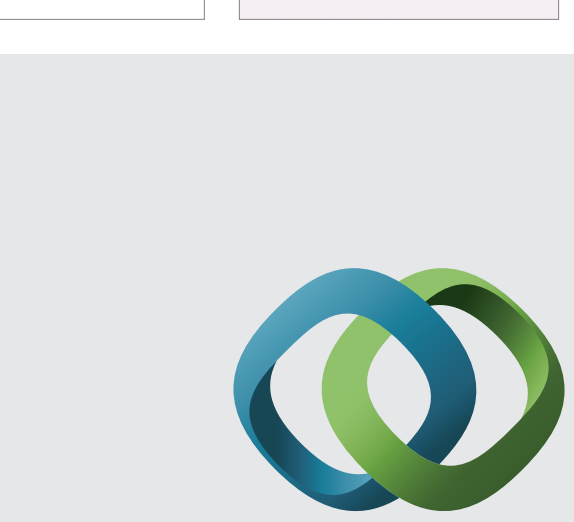

\section{Hindawi}

Submit your manuscripts at

http://www.hindawi.com
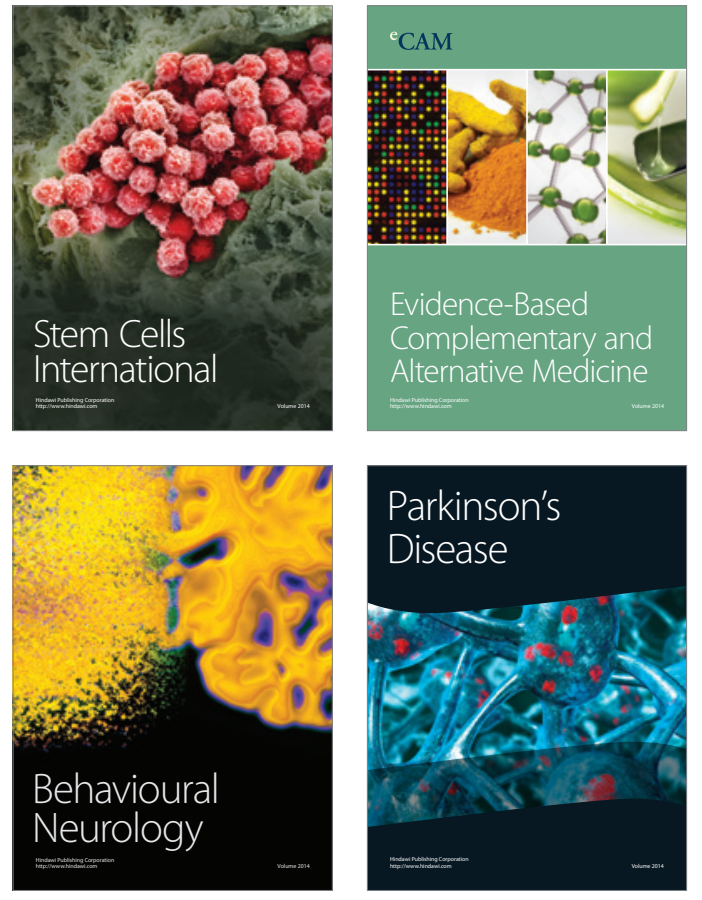
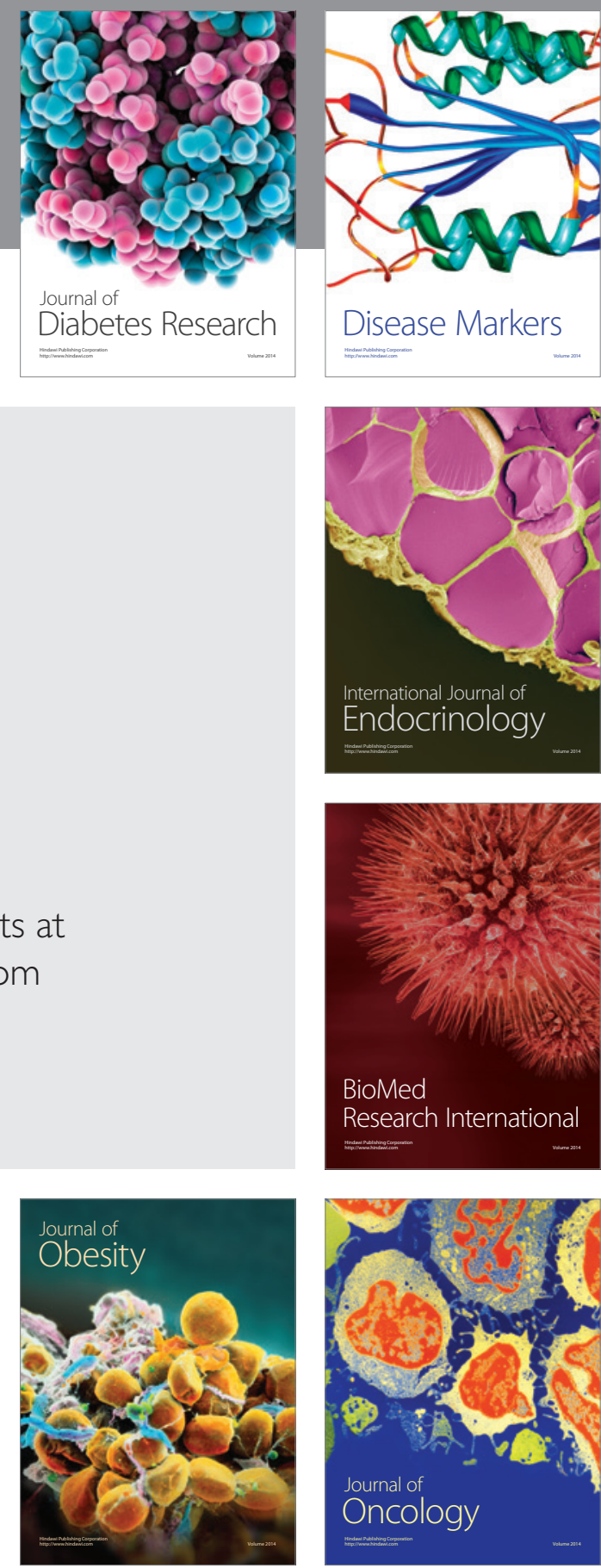

Disease Markers
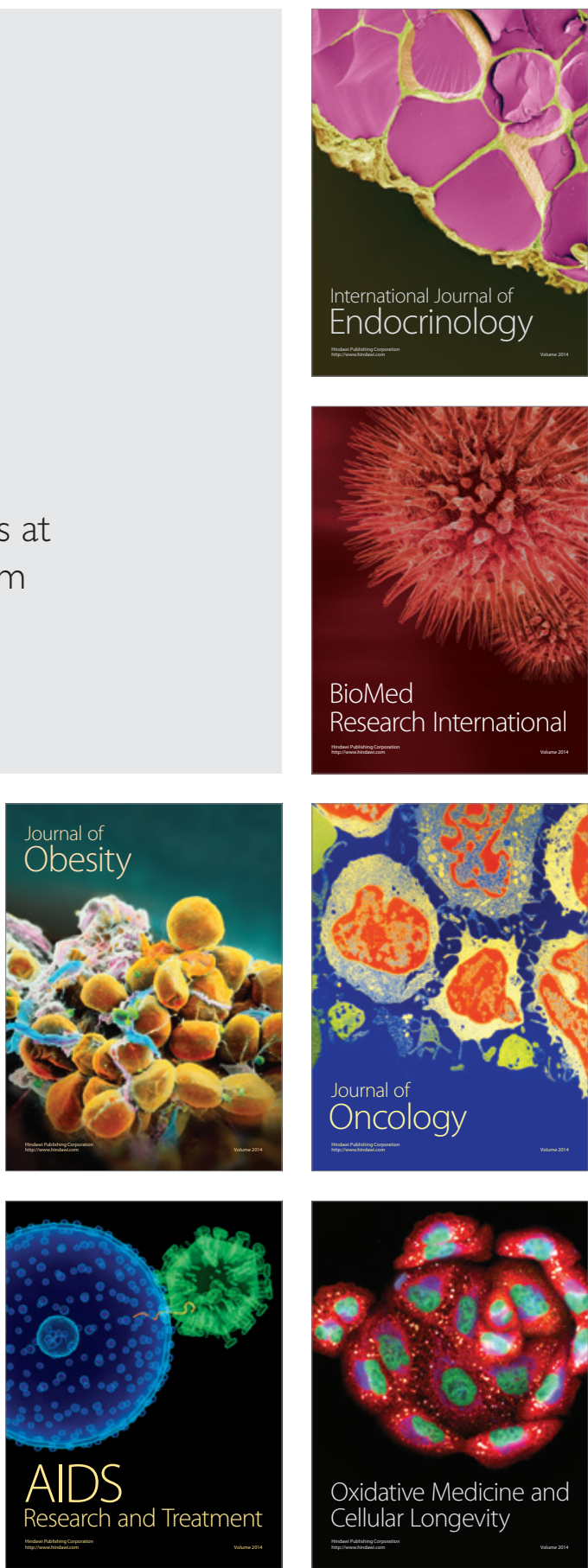